\title{
Canada's research manpower
}

from Richard Pearson

\section{A boom in jobs in research and development is forecast in Canada, but these will be in the new technologies and industry. Traditional academic careers will remain hard to get.}

THE Canadian government, like many others, is committed to significantly increasing the level of research and development in the country and the adoption of new technology. Such progress, however, is seen to be conditional on the availability of highly skilled personnel; even if the technology is imported, highly skilled personnel are still needed to apply it effectively.

In 1979 the Canadian government set a target to increase expenditure on research and development to reach 1.5 per cent of the gross national product (GNP) within five years. In the event this was not achieved and the total expenditure in 1984 , \$C5,000 million, represented only 1.25 per cent of GNP. The growth in research manpower fell similarly short of target, the number increasing by only 8,000 to total the equivalent of 28,000 fulltime scientists and engineers in research in 1984. Over half were employed in industry, which has shown the fastest growth in research personnel over the past decade, while one-quarter were in government employment and 16 per cent in the universities (Table 1).

The latest assessment of the adequacy of Canada's research manpower resources up to 1990 , in a report issued by the

\begin{tabular}{cccc}
\hline \multicolumn{4}{c}{ Table I Scientists and engineers in research } \\
and development \\
\hline Year & $\begin{array}{c}\text { Government } \\
\text { Industrial }\end{array}$ & University \\
1975 & 5,990 & 8,320 & 3,840 \\
1976 & 6,160 & 9,020 & 3,960 \\
1977 & 6,250 & 9,720 & 4,030 \\
1978 & 6,430 & 10,520 & 3,750 \\
1979 & 6,410 & 11,310 & 4,140 \\
1980 & 6,440 & 12,980 & 4,210 \\
1981 & 6,610 & 14,640 & 4,160 \\
1982 & 7,320 & 15,900 & 4,390 \\
1983 & 7,467 & 16,165 & 4,387 \\
1984 & 7,572 & 16,093 & 4,416 \\
\hline
\end{tabular}

*Full-time equivalents including BSc, MSc, PhD (natural sciences and engineering only).

National Sciences and Engineering Research Council of Canada, raises serious concern about future manpower constraints.

Using a model which can test a range of possible assumptions, such as differing rates of economic growth, levels of investment in research, 'productivity' of researchers, and the effective working life of researchers, the council's report argues that the supply of research talent "would be inadequate to meet the requirements, even with a fairly modest growth in $\mathrm{R} \& \mathrm{D}$ expenditures. It would be adequate only under less desirable conditions such as no or very slow economic growth". The imbalances were found to be most serious for applied scientists and engineers, new researchers with research qualifications, and staff in areas such as computer science and biotechnology, where shortages were expected under any scenario.

Annual demand for new PhD students could rise as high as 3,000 per year modelled on scenarios of high growth and rising expenditure on research and development, or be as low as 600 per year with no growth in research or GNP. The corresponding figures for $\mathrm{MSc}$ students range from 1,300 to 3,800 , and both sets of figures showed marked differences according to discipline. As there was believed to be a plentiful supply of BSc students, detailed projections were not made.

Traditionally, the majority of new researchers have come from the ranks of newly qualifying graduates and postgraduates. Last year there were over 16,000 full-time postgraduates studying relevant disciplines in Canadian universities, a dramatic increase on the 11,000 five years earlier. However, one-third of the growth was accounted for by foreign students, with nearly all of the increase in the applied sciences and engineering coming from overseas students. In 1984 they accounted for over half the students in these subjects and more than one in three studying physical sciences and mathematics, a pattern not dissimilar to that found in the United States and Britain. In Canada, were it not for this growth, many university departments would have had problems maintaining their graduate program. mes and research.

Looking forward, the number of postgraduates is already largely determined for the period to 1990 , given the long lead times necessary to adjust university programmes. The number of Canadian postgraduates awarded MScs is expected to rise from 2,500 in 1984 to 3,900 in 1990 , but less than half are expected to enter employment directly. The corresponding figures for $\mathrm{PhDs}$ are 670 , rising to 994 , although all of the PhDs are expected to seek work, postdoctoral work being regarded as employment. The average annual supply of postgraduate researchers entering the labour market over the next five years will be around 1,950 at the MSc level and 850 PhDs, but under half are in the shortage subject areas of applied sciences and engineering (Table 2).

The council believes that the shortages that will exist under any realistic scenario can be reduced only by a combination of factors. These include raising the productivity of researchers (measured as less researchers per unit of research expenditure) and increasing the inflow of suitably

Table 2 Average annual supply of postgraduates $1984-90$

\begin{tabular}{lcc}
\hline & MScs & PhDs \\
Applied sciences and engineering & 906 & 198 \\
Physical sciences and mathematics & 418 & 295 \\
Agricultural and biological sciences & 314 & 211 \\
Health professions & 314 & 139 \\
Total & $\mathbf{1 , 9 5 2}$ & $\mathbf{8 4 2}$
\end{tabular}

Source: Research Talent in the Natural Sciences and Engineering, Supply and Demand Projections to 1990 (NSERCC, 1985).

qualified staff from jobs not connected with research and giving them appropriate retraining, although this latter option is not thought likely to yield significant results if US experience is repeated. As the growth in research posts is largely centred on industrial needs, another route is for companies to upgrade the research skills of existing staff, particularly those at first-degree level. If this were to be done in collaboration with university programmes, the universities themselves would be beneficiaries of industrial experience. While immigration is not seen to be a solution, given worldwide shortages, a more productive opportunity could be to make it easier for overseas students to stay on in Canada by relaxing immigration criteria.

Within the education system, one major constraint on increasing the supply of new postgraduates is that there are not enough qualified students in the pipeline were the postgraduate funding programme to be increased. There is thus a longer-term need to improve science teaching in schools and to encourage mos 2 students, particularly women, to stury relevant subjects.

Demand in key disciplines such as computer science, biotechnology and specialist engineering is expected to grow particularly. fast, and much of the growth in research jobs will be in industry rather than academia or government. As such, potential entrants to research and development will have to have an education that permits flexibility to be able to respond to changing needs and will have to look beyond the traditional career routes to benefit from any research boom

Richard Pearson is at the Institute of Manpower Studies, Mantell Building, University of Sussex, Brighton BN1 9RF, UK. 